\title{
Efficient Use of Water under Irrigation Management Practices for Surface Irrigated Rice
}

\author{
Rick Donald S. Manzon ${ }^{1}$, Mike Santos ${ }^{2}$, Leica Infante ${ }^{3}$, Jerald F. Silao ${ }^{4}$, Keith Russel E. Soriano ${ }^{5}$ \\ 1,2,3,4,5 Nueva Ecija University of Science and Technology Gen. Tinio Street, Cabanatuan City 3100
}

\begin{abstract}
With the continuous climate change we are experiencing; extreme heat, drought, and declining water supplies that affect our rain fed and irrigation systems resulting to a higher demand for water for evaporation and evapotranspiration by crops which lead to more frequent soil moisture deficit which is unavoidable and there are still other factors that contributes to water head loss. This make it necessary to find out novel ways to resolve the issues regarding irrigation management. Though there are many existing innovative water management ideas available out there, but it takes to shed huge amounts of government funds to implement. This study consists of designing a water-recycle model to efficiently use the limited water supply and further attain to serve the total surface area of irrigated rice. The proposed design uses a renewable energy that pumps out water from the catch basin back to its water source, this method entirety use the most out of the water supply to lessen water wastage and water shortage and to maximize water saving in the area.
\end{abstract}

KEYWORDS: Water-recycle model, renewable energy powered pump, service area, seepage, infiltration, percolation

\section{INTRODUCTION}

As the demand of water arises to irrigate agricultural lands in the Philippines, one of the major issues being confronted is the continuous heat waves we are experiencing causing evaporation, transpiration and evapotranspiration of water on reservoirs, canals and crops, changes in precipitation patterns, and the reductions in water availability due to climate change in which, it is unavoidable. Other principal factors that contributes to water head loss from earth canals during irrigation are water seepage, infiltration and percolation. Though the losses from these factors can be reduced by applying concrete lining to the canals, but these costs millions of pesos to construct and implement.

National Irrigation Administration is a government agency in the Philippines that handles irrigation services to its farmer beneficiaries. The agency are the ones that operates and maintain irrigation systems throughout the country.

Its main goal is to provide sustainable irrigation services aimed towards the highest satisfaction in the improvement of the farmer's income and quality of life. The agency itself is finding innovative ways on how to de-escalate the wastage of water during irrigation. The present study aims at designing a model on how to entirety use the most out of the limited water supply. The objective is to create a water-recycle model using renewable energy or a water cycle in the irrigation system.

\section{LITERATURE REVIEW}

As we approach the 21 st century, more than a quarter of the world's population or a third of the population in developing countries live in regions that will experience severe water scarcity due to climate change. Irrigation consumes or depletes over $70 \%$ of the total developed water supplies of the world. Many people believe that existing irrigation systems are so inefficient that most-if indeed not all-of future needs for water by all the sectors could be met by increasing the efficiency of irrigation and again recycle the water saved in irrigation to reuse it. (Barke et.al, 1998)

When a water basin is diverted from a source to a particular use, two things happen to it. First, a part is lost due to the atmosphere because of evaporation from top surface areas, or evapotranspiration from crops, or both. Second, the part of the diverted water that has not evaporated drains to surface or sub-surface areas. The drainage water flows back into a stream or to other surface and subsurface areas or it will infiltrate the soil ground where it can be captured, recycled and reused as an additional source of supply. This water is not lost or wasted in physical terms. (Seckler, 1996)

Common water saving practices is by using a concrete as lining material for the full section and at the sides of the canal. The conveyance loss of the canal decreased from $2 \mathrm{~mm} /$ day to $0 \mathrm{~mm} / \mathrm{day}$, and the amount of silt deposition was also reduced. Besides this, the quantity of seepage losses was decreased significantly. (Facon, 1997)

A good modern design requires a thought and analytical process that starts with the definition of the desired level of water delivery service to farmer beneficiaries throughout the irrigation system. It then makes full use of advanced and innovative concepts in hydraulic engineering, agronomic science, renewable energy, irrigation engineering, economics and social science to identify the simplest components and a 
workable solution to the rising problem. Adapting to Modernization is a complete process and is not to be confused with merely installing new physical components in a system such as a canal lining or automatic gates. (Burt, 1997)

\section{PROPOSED METHODOLOGY}

The main goal of the proposed design water irrigation cycle is to create an innovative and hybrid model for efficient use of water for irrigation of rice field in the Philippines. The model will be using renewable energy powered pump for extracting, recycling or reusing of drainage water. This will help the agency that operates irrigation management to fully utilize the limited water supply in their area. The proposed model consists of the following water irrigation cycle that shows the efficient use of water for irrigation management as shown in Figure 1.

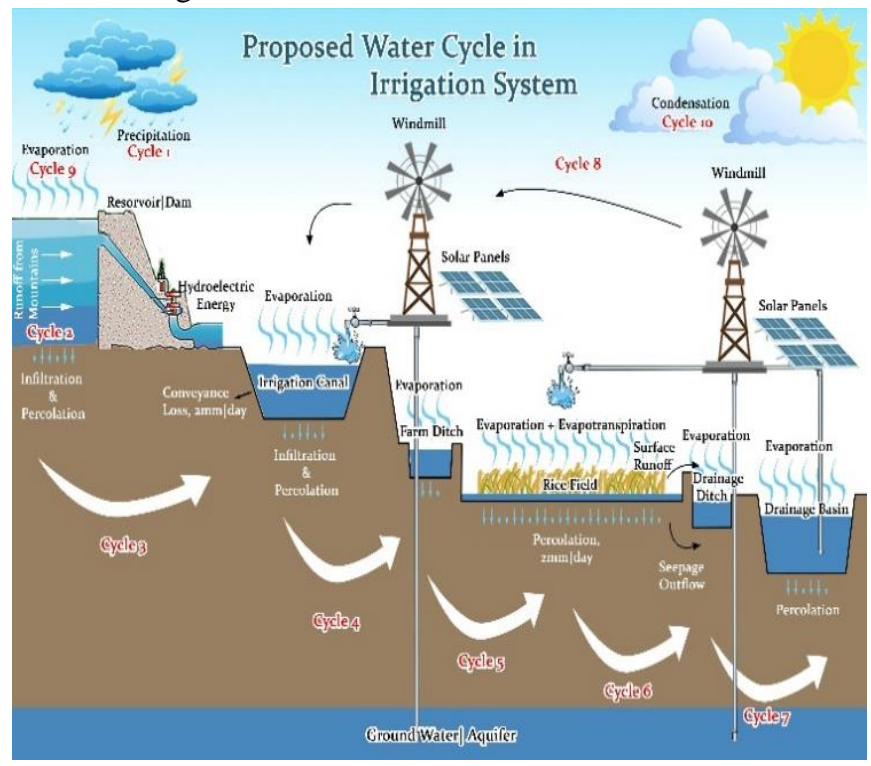

Figure 1. Proposed Model of Water Cycle in Irrigation System

\section{Cycle 1: Precipitation}

The first cycle is the precipitation that acts as the main water source of reservoir/dams that will be used to irrigate agricultural lands.

\section{Cycle 2: Surface Run-off from mountains}

Another source of reservoir/dams are the water run-off from mountains. The ratio of Reservoir Storage Efficiency is normally less than 1.0 because of the considerable amount of water loss inside a reservoir caused by infiltration/seepage and percolation (Ideal percolation rate is $5 \mathrm{~mm} /$ day, source: National Irrigation Administration).

\section{Cycle 3: Release of Water from Reservoir to Irrigation Canal}

Releasing of water from reservoir can produce renewable energy and this is the first step in irrigating agricultural lands. Cycle 4: Irrigation Canal carries water to reach Agricultural lands through a farm ditch

In this cycle, water head losses are already present due to water seepage, infiltration and percolation on earth canals, an average of $2 \mathrm{~mm}$ conveyance loss (source: National Irrigation
Administration) are generated per day. Another factor for head loss is the evaporation on the water surface area of the canal. Seepage loss can be totally reduced by using a concrete lining on the perimeter section of the canal.

\section{Cycle 5: Water from Farm Ditch Reaches Rice Fields}

Main objective of irrigation is to irrigate the rice fields regularly for it to produce higher yields of rice crop. But due to the seepage loss, conveyance loss, percolation rate, and evaporation rate along the way, large amount of water head loss had been deducted before it reaches the rice fields. The drainage of water caused by these natural phenomena can cause water scarcity especially if the reservoir has a limited supply of water affecting the end portion of the service area. Cycle 6: Evapotranspiration Rate and Surface Drainage Loss from Rice Fields

Rice crops only uses less than $5 \%$ of the water absorbed (source: National Irrigation Administration), the rest is lost to atmosphere through transpiration from plant leaves. Surface Drainage Loss are also present due to the oversupply of water in the rice fields especially one's closer to the reservoir and irrigation canals.

Cycle 7: Water on Drainage Ditches / Turnouts ends up on Drainage Basin

Drainage Ditches destination is the Drainage basin that collects all unused water. The water in this basin doesn't usually used and it will end up draining its water to creeks and other bodies of water.

Cycle 8: Recycling drainage water through the use of renewable energy powered pump

The water drains due to the head loss caused by seepage, percolation and surface drainage. This water is technically not lost or wasted and can be reused or recycle again by extracting those water from the ground / drainage basin using a renewable energy powered pump (Solar panels or windmills). This process can help solve the water scarcity and can be fully utilize and efficiently use the available water within the area. The procedure is to construct a windmill driven pump or a solar powered pump irrigation system in certain areas to collect again all the water loss and pump it to irrigation canals or rice fields. The operation cycle will only repeat itself: Irrigate, percolate, and water pumping.

\section{Cycle 9: Evaporation}

Water quickly evaporates on a greater water surface area. The larger the surface area, the more water vapor it releases due to the solar radiation. Other water saving methods for this cycle is (1) by constructing a shade on the surface of the water such as floating solar panels to reduce the evaporation rate (2) by installing atmospheric water generator around a reservoir that extracts water from humid ambient air that turns into a potable water.

\section{Cycle 10: Condensation}

Once the water vapor cools down, it will now turn into a denser liquid that form into clouds and will further go back to the ground by precipitation. 


\section{RESULTS}

In the proposed model of water cycle in Irrigation System, renewable energy powered pump system are used to make it more sustainable and less carbon footprint rather than using the traditional diesel engine water pump machine that is only limited to irrigate a specific area, consumes higher costs for farmers and leaves more carbon monoxide in the atmosphere. The Model of Water Cycle can retrieve the water loss caused by seepage, drainage and percolation back to the ground surface for irrigation.

By constructing this renewable energy powered pump in particular spots of the service area of the reservoir as shown in Figure 2, this will act as the new water source for rice fields and other crops especially in situations where the water in reservoir is insufficient to reach the tail ends portion of irrigation canals and distant rice fields of the total service area. The availability of water will be accessible to farmers all year round; this also is advantageous to the agency for irrigation services to serve the farmer beneficiaries on times of water delivery cut-off.

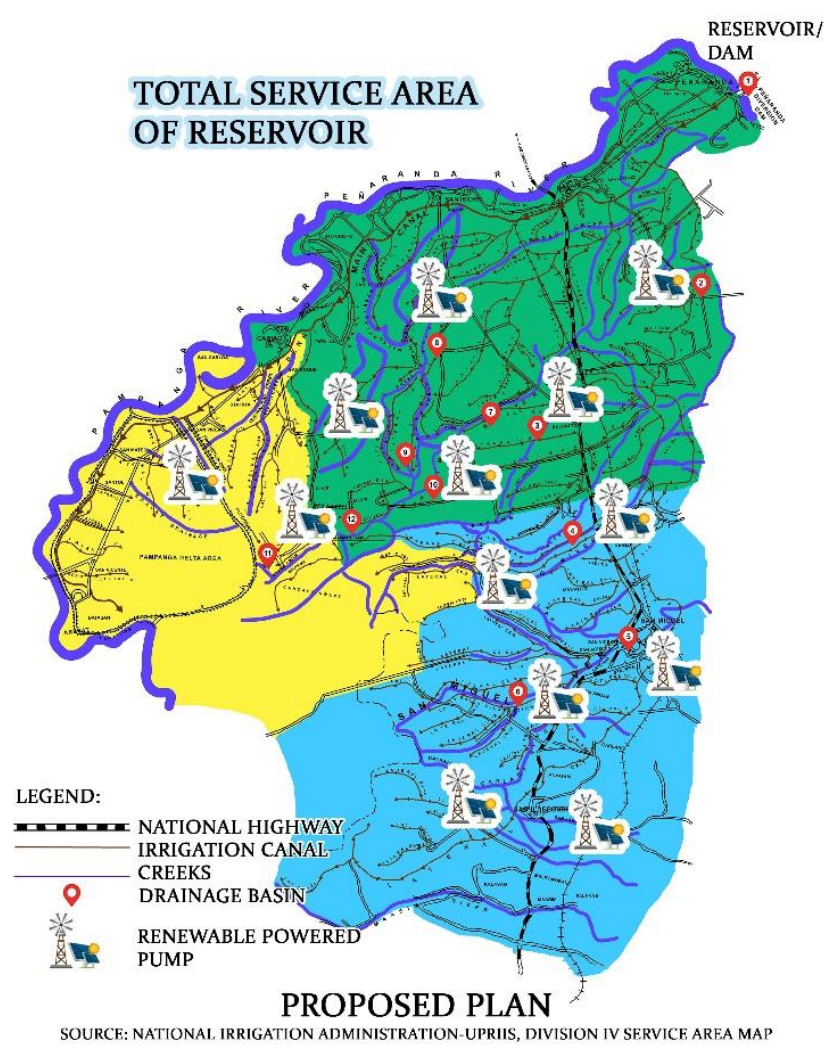

Figure 2. Sample Locations of Renewable Energy Powered Pumps

\section{FUTURE WORKS}

In this paper, the researchers created a water cycle model in irrigation system to fully utilize the most out of the available water. In future, other researchers can identify the specific locations within the service area to put this renewable energy powered pumps. Each pumps must cater an identified rice field area, from it the researchers can count the total number of renewable energy powered pumps to be installed within the service area.

\section{CONCLUSIONS}

The proposed model is designed with the aim of using the most out of the available water supply within the service area. The main objective of this study is to reuse and recycle the water loss from seepage and percolation during water delivery. With the use of sustainable energies to extract the water that drains into the ground, more farmers will be much more accessible to water whenever they need it in irrigating their land. To evaluate our model, actual construction must be implemented within the irrigation system to verify the effectivity of this irrigation management practice.

\section{REFERENCES}

1. D. Seckler (1996). The New Era of Water Resources Management: From "Dry" to "Wet" Water Savings, IWMI Research Paper 1.

2. D. Seckler, D. Molden, and R. Barke (1998). Water Scarcity in the Twenty-First Century, IWMI Water Brief 1.

3. T. Facon, (1997). Modernization of irrigation schemes, synthesis of country papers, In: FAO Water Report 12, Modernization of Irrigation schemes, past experiences and future options.

4. Burt, C.M. (1997). Modern water control and management practices in irrigation: methodology and criteria for evaluating the impact on performance. in Modernization of irrigation schemes: past experiences and future options. RAP Publication 1997/22. Water Report 12. FAO. pp 89-102 